\title{
The Working Mechanism of Conceptual Blending Theory in Metaphor Understanding
}

\author{
Zhao Zhuang ${ }^{1, *}$ \\ ${ }^{1}$ Yunnan University of Business Management, Kunming, Yunnan 650300, China \\ *Corresponding author. Email: 360379250@qq.com
}

\begin{abstract}
Cognitive linguistics is an approach to language that is based on people's experience of the world and the way people perceive and conceptualize it. Metaphors abound in Mao Zedong's poems. These frequent and substantive metaphors play an important role in expressing the theme of the poetry. The author of this paper attempts to study the metaphors in Mao's poems from the perspective of cognitive linguistics, especially from the conceptual blending theory, on the premise of understanding metaphors comprehensively, and testifies the conceptual blending theory's explanatory power in cognitive linguistics.
\end{abstract}

Keywords: conceptual blending theory, metaphors, Mao Zedong's poems

\section{INTRODUCTION}

Cognitive linguistics began to emerge in the 1970 s and has been increasingly active since the 1980s. According to Karen van Hoek (2003), cognitive linguistics is best characterized as a paradigm within linguistics. During the development and maturing stage of cognitive linguistics, it subsumes a number of distinct theories and celebrated names, such as the studies on metaphor (Lakoff \& Johnson, 1980), mental space theory (Fauconnier, 1985), Langacker's cognitive grammar (Langacker, 1991), construction grammar (Glodberg, 1995), and Croft and Curse (Croft \& Cruse, 2004) give a rough definition of paradigm with three major hypotheses that the cognitive linguistic approach to language, and so on.

Within cognitive linguistic theories, conceptual metaphor theory and conceptual blending theory have proposed new ways of researching the processes of meaning construction. The conceptual blending theory, also known as conceptual integration theory, which proposed by Fauconnier and Turner based on Lakoff's conceptual metaphor theory. Fauconnier's theory is a further development of metaphor.

\section{METAPHOR IN COGNITIVE} \section{LINGUISTICS}

Lakoff and Johnson make the distinction between conceptual metaphors and linguistic metaphors. Linguistic metaphors are merely surface manifestations of conceptual metaphors. While, conceptual metaphors function to produce linguistic metaphors. And conceptual metaphors include structural metaphors, orientational metaphors and ontological metaphors. Lakoff and Johnson lay emphasis on the study of conventional metaphors. Conceptual metaphor theory opens a new field for contemporary theory of metaphor, which provides people a new perspective to experience the world. Based on the CMT, Gilles Fauconnier and Mark Turner introduce a new analytic framework. They propose conceptual blending theory (CBT). This operation is also called 'conceptual integration' by them. In this theory, metaphorical mapping takes place by mental spaces. Mental space is defined as temporary representations constructed by speakers when they conceive of an experience, real and imagined.

I. A. Richards is the first modern author who unambiguously argues for the conceptualist research vein for metaphor. As Richards concerns, linguistic metaphors are really reflected by some mundane things. "Thought is metaphorical, and proceeds by comparison, and the metaphors of language derive there from." (Richards, 1967, p.94) During the long period of research of metaphor, the real breakthrough is made by the cognitivists. The starting point within the field of cognitive linguistics approach to metaphor is from the book Metaphors We Live By. It proposes conceptual metaphor theory. The fundamental notion of conceptual metaphor theory is the 'mapping'. Mapping is as the feature from a source domain to a target domain. This mapping is ubiquitous, 
unidirectional, systemic, invariable and grounded in physical and socio-cultural experience. (Lakoff \& Johnson, 1980). The author devotes to explain the working mechanism of conceptual blending theory. And the author of this thesis will look at the conceptual blending theory from the following aspects, for example, its network model, the operation of the spaces, blending process and emergent structure. This part puts emphasis on how efficient the conceptual blending theory is in the understanding of the two different languages. The English version (Chinese and English version) of Poems of Mao Zedong is selected and taken as the main source of data translated by $\mathrm{Gu}$ Zhengkun. (Gu Zhengkun, 2010)

\section{CONCEPTUAL BLENDING THEORY APPLIED INTO ANALYZING THE METAPHORS}

Sample 1: 烟雨莽苍苍, 龟蛇锁大江 ("Pu Sa Man Yellow Crane Tower")
This poem is written in the year of 1927, in this period, Chiang Kai-shek launched a devastating attack upon the Chinese communists. However, Chen Duxiu instead of staging a counterattack against Chiang, insisted on making concession to Kuomintang and give up the Party's leadership over the revolution. Mao Zedong's proposals about this issue were ignored and he was actually excluded outside the Party leadership. When Mao Zedong boarded and overlooked the Yellow Crane Tower, he expressed his feelings and thoughts.

In sample one, the Mountain Tortoise and the Mountain Snake are metaphorically refer to 'Tortoise' and 'Snake'. Both the two Mountains look like tortoise and snake in their shapes, and located opposite to each other. Between them is the Yangzi River, which seems that the river is surrounded by the two Mountains in chain. The four spaces in blending network can give the intuitive explanation in the following "Table I".

TABLE I. CONCEPTUAL BLENDING NETWORK: "TORTOISE AND SNAKE HOLD THE GREAT RIVER LOCKED"

\begin{tabular}{|c|c|c|}
\hline Generic Space & \multicolumn{2}{|c|}{ shape, appearance } \\
\hline Input Space 1 & \multicolumn{2}{|c|}{ The animal tortoise and snake } \\
\hline Input Space 2 & \multicolumn{2}{|c|}{ The Mountain Tortoise and the Mountain Snake } \\
\hline \multirow[t]{5}{*}{ Blended Space } & \multirow[t]{2}{*}{ participants } & the mountain Tortoise and the Mountain Snake \\
\hline & & the animal of tortoise and the snake \\
\hline & relationship & "snake and tortoise" like a chain surround and hold something \\
\hline & \multicolumn{2}{|c|}{ The mountain Snake zigzags like a snake } \\
\hline & \multicolumn{2}{|c|}{ obstacles blocked the path of revolutionary } \\
\hline $\begin{array}{l}\text { Emergent } \\
\text { Structure }\end{array}$ & \multicolumn{2}{|c|}{$\begin{array}{l}\text { the Yangzi River is bound by the two mountains; obstacles and difficulties in the course of } \\
\text { advance }\end{array}$} \\
\hline
\end{tabular}

In this poem, the description of the two mountains stand facing each other and hold the Yangzi River literally which implies that the raging tide of revolution surges forward. The metaphor results from the blend which contains the two input spaces: the source space of the animal tortoise and snake and the target space of the Mountain Tortoise as well the Mountain Snake. The input space 1 provides the organizing frame to the blend; while input space 2 is the focus of understanding. There are partial cross-space mapping of counterpart connections between input spaces. The appearances of snake and tortoise are used to name the mountains. Both of them show the similar characteristics of encirclement.

In the generic space which maps onto both input spaces reflects the common structures shared by the two inputs: both spaces contain the information that the same shape and appearance in each input space.

Structure from two input mental spaces is projected to the blend. Blending composes elements and relations from the two inputs. The Yangzi River flows between the two Mountains can be inferred the implied message that revolution is like a huge vessel under the rule of erroneous ideas, which may lead the dangerous of revolution strike on the rock. No matter what kind of difficulties the Communist Party meets with, the revolutionary enthusiasm wouldn't extinguish. The emergent structure through composition, completion and elaboration is brought out. The current situation is tense, obstacles and difficulties in the course of advance, but the revolutionaries always maintain a positive mental outlook.

Sample 2: 从头越, 苍山如海, 残阳如血 ("Yi Qin E The Pass of Mount Lou")

The Pass of Mount Lou, historically a key pass, is situated to the north of Zunyi, Guizhou Province. After the Zunyi Meeting held in January 1935, Mao Zedong's leadership was established in the Chinese Communist Party. The Red Army on the long march seized the Pass of Mount Lou for twice. Although the strategic mission of the long march meets with setback, the battle of the Pass of Mount Lou, the Red Army is of victory. The brave and heroic of the Red Army as well as the revolutionary optimism spirit of the poet encourages them facing of difficulties. ("Table II") 
TABLE II. CONCEPTUAL BLENDING NETWORK: "THE ROLLING HILLS SEA-BLUE, THE DYING SUN BLOOD-RED"

\begin{tabular}{|l|l|l|}
\hline Generic Space & $\begin{array}{l}\text { Characteristics: the shape of a stretch of hills; mountain peaks and its valley; the endless } \\
\text { sea; the color of setting sun; the boundless beauty of sunset; the magnificent sight of the } \\
\text { setting sun. }\end{array}$ \\
\hline Input Space 1 & the sea; the blood \\
\hline Input Space 2 & the mountains; the setting sun \\
\hline Blended Space & participants & the mountains and the setting sun \\
\cline { 2 - 3 } & the sea and the blood \\
\cline { 2 - 3 } & relationship & The rolling mountains look like the continuous waves. \\
\cline { 2 - 3 } & The color of sunset looks like the blood. \\
\cline { 2 - 3 } & The stretches of mountains are resemblance to the sea. \\
\cline { 2 - 3 } & The color of sunset is resemblance to the blood. \\
\hline Emergent & $\begin{array}{l}\text { The Red Army and their leaders regard danger as nothing. The Red Army share life and } \\
\text { Structure }\end{array}$ &
\end{tabular}

In these metaphorical verses, the partial mapping of counterparts is formed between the input space one and input space two. The similar points of the two input spaces compose of generic space, the same characteristics shared from the two spaces; the shape of a stretch of mountain is as alike as the sea, as well as the sunset is similar in color to blood. The generic space reflects crossspace projections of counterpart connections. In the two spaces, the image of mountain is magnificent and mighty, which is the like of the sea. The sunset and its color are also grandeur and beauty, which show a sense of stateliness. The blood, itself, can convey information of solemnity and seriousness. Therefore, the counterpart connection between the sunset and the blood may be existed.

As conceived within conceptual blending theory, blending involves three basic processes, namely 'composition', 'completion' and 'elaboration'. Composition is the most straightforward process. The projection of content from each of the inputs into the blended space, such as the mountain, the sea, the sunset and blood, is composition. Completion is the filling out of a pattern in the blend, for example, when people mentally project the shape of a stretch of hills to the sea, and the color of sunset to the blood, people end up introducing the notion of merely description of natural views and easy, pleasant mood. The completion process is often a source of emergent content in the blend. Elaboration is the simulated mental performance of the event in the blend. Through the previous process, the imagine scenarios unfolds along possible elements. Therefore, the emergent structure deduces the possible meaning that the Red Army and their leaders regard danger as nothing and they always invincible.

\section{CONCLUSION}

Conceptual blending theory is one of the major schools of cognitive theory. The nature of mapping between domains has enjoyed sustained attention as a central problem of cognitive science. Conceptual blending theory plays a significant role in cognition. "It has uniform, systematic properties of structure and dynamics." (Fauconnier, 2010, p.189).

A basic assumption of the possibility of translation, which means meaning can be communicated to some degree in both the source and the target languages, has been challenged more than once on the realm of linguistic and philosophical. Sager makes the points that "all the arguments for and against the possibility of translation can be reduced to a question of the scope of the definition of the concept [of translation]." (Sager, 1993, p.131) Sager proposes his idea on translation that translation possibility is a relative concept. That is to say, "degrees of translatability as defined by the existence (or absence) of units of equivalence between the source and target languages at different levels of analysis." (Wang, 2004, p.152). Translation among different languages is feasible.

Although people use different languages from all over the world to express their ideas, the cognition they possessed is the same. Thus, metaphors can convey the implied meaning through different languages, as well as different strategies.

\section{References}

[1] Richards, I. A. (1967). The Philosophy of Rhetoric [M]. Oxford University Press.

[2] Lakoff, G. \& M, Johnson (1980). Metaphors We Live By [M]. Chicago and London: University of Chicago Press.

[3] Gu, Zhengkun. (2010). Poems of Mao Zedong Rhymed Versions with Annotations [M]. Beijing: Beijing University Press.

[4] Fauconnier, G. (2010). Mapping in Thought and Language [M]. Beijing: Beijing World Publishing Corporation.

[5] Sager, J. C. (1993). Language Engineering and Translation: Consequences of Automation [M]. Amsterdam: Benjamins.

[6] Wang, Bin. (2004). Translation and Conceptual Integration [M]. Shanghai: Donghua University Press. 